18. ¿Conclusiones? Un trabajo que nace de la recopilación de algunas observaciones a un fragmento de libro no necesita de conclusiones stricto sensu. En mi opinión habria sido mucho mejor, si la voluntad de la Dra.Guardia era publicar los apéndices con las inscripciones de los pavimentos musivos estudiados por ella, que hubiera realizado una lectura más crítica y rigurosa de esas inscripciones. Su trabajo en el campo de la iconografía es realmente importante y no hacia ninguna falta enturbiarlo con una información imprecisa y no pocas veces incierta. Si sus ediciones hubieran sido fiables, su trabajo global hubiera resultado doblemente valioso, porque hubiéramos encontrado en un solo volumen una correcta edición de textos y un mejor comentario de las imágenes a que acompañan, y esa es, a no dudarlo, la mejor manera de comprender una inscripción musiva.
No me complace especialmente escribir páginas como éstas, pero pienso que es mucho mejor corregir los errores de lectura publicados por la Dra.Guardia que no pensar que los lectores no especializados en el tema van a recibir una información incorrecta. Tómense estas páginas como un complemento al dossier de los mosaicos bajo-imperiales en Hispania ${ }^{34}$.

\footnotetext{
${ }^{4}$ Créditos de las fotografias:

figura I: foto de IRC II, pl.VIII.

figura 2: foto de J.Gómez Pallarès

figura 3: foto de J.Gómez Pallarès

figura 4: foto de Foto Estudio Tria, Jaén.

figura 5: foto de Donderer 1989. Taf.40.2

figura 6: fotos del Área de Difusión del Conjunto Arqueológico de Itálica.

figura 7: fotos de J.Gómez Pallarès.
}

\title{
LATE ROMAN UNGUENTARIUM: UNGÜENTARIOS CRISTIANOS DE LA ANTIGÜEDAD TARDÍA PROCEDENTES DE PUNTA DE L'ILLA DE CULLERA, VALENCIA'
}

\author{
POR \\ M. ${ }^{\mathrm{a}}$ ISABEL GARCIA VILLANUEVA \\ MIQUEL ROSSELLÓ MESQUIDA \\ Servicio de Investigación Arqueológica Municipal de Valencia (S.I.A.M.)
}

RESUMEN

Presentamos en este articulo un conjunto de ungüentarios cerámicos de origen oriental de la Antigüedad Tardia procedentes de Punta de I'Illa de Cullera, Valencia. El interés de estas piezas viene dado por ser la primera vez que se documentan en la Península y su posible relación con algún aspecto de la liturgia cristiana.

' Queremos agradecer al Servicio de Investigación Prehistórica de ta Diputación de Valencia y especialmente a su Director, Dr. Bernat Marti Oliver, las facilidades y el
SUMMARY

In this paper we want to present a type of pottery production (Late Roman Unguentarium) characteristic of the Eastern Mediterranean area from the sixth and seventh century A.D., found at "Punta de I'Illa de Culleran site, in Valencia.

interés mostrado en la realización de este trabajo. Asi mismo, agradecemos al Dr. Luis Caballero Zoreda y a Dña. Rafaela Soriano Sánchez la preocupación e interés en la elaboración de este artículo. 


\section{INTRODUCCIÓN}

El término Late Roman Unguentarium fue adoptado por J. W. Hayes para designar un tipo de ungüentario cerámico que aparece regularmente en yacimientos de los siglos vi y vil d. C. en la parte oriental del Mediterráneo y diferenciarlo del común ungüentario fusiforme de época helenistica, en vista a su general $\operatorname{similitud}(\mathrm{Ha}-$ yes, 1968: 212, 214).

Estos pequeños frascos cerámicos tienen una altura de alrededor de $\operatorname{los} 20 \mathrm{~cm}$., presentan una forma fusiforme, pequeña boca tubular diferenciada del cuerpo por una fina moldura y cuerpo apuntado hacia el pie, acabando en una base truncada burdamente. Un aspecto interesante de estas piezas es que algunas de ellas exhiben una pequeña estampilla circular o rectangular en la zona del pie con variada temática, mayoritariamente epigráfica (letras ligadas, monogramas...), apareciendo también motivos animales de clara simbologia cristiana.

Desde un punto de vista técnico su manufactura es muy caracteristica, tanto por la pasta como por el tratamiento exterior que presenta. La cerámica es de grano muy fino y de fractura recta y afilada, percibiéndose ocasionalmente algunas inclusiones de pequeños puntos de cal. Presenta líneas muy marcadas de torno, visibles en el interior de las piezas, al contrario de la superficie externa que aparece bien alisada. El color de la pasta es muy variable dependiendo del grado de cocción de la misma, siendo normal las tonalidades anaranjadas, rosadas, marrón-rojizas, púrpuras y grises, apareciendo con frecuencia piezas con un corazón gris conjuntamente con una superficie rojiza, y viceversa. Otro aspecto a destacar es la presencia en la parte superior de la superficie externa de las piezas de un ligero engobe de tonalidad algo más oscura que cae en forma de goterones (Hayes, 1971: 243).

\section{CONTEXTO}

Las piezas cerámicas que aquí presentamos proceden del yacimiento costero de Punta de I'Illa de Cullera, población situada a unos cua- renta kilómetros al sur de la ciudad de Valencia (figura 1). Esta antigua isla fue unida a tierra firme con la construcción de un dique en el siglo XVIII. Por otra parte, el yacimiento fue arrasado por la construcción de un gran edificio en décadas pasadas.

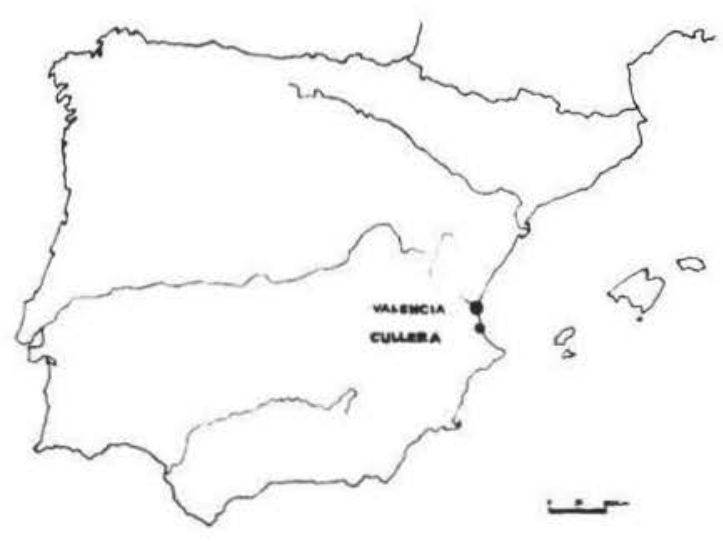

Figura 1. Situación de Cullera en la Peninsula lbérica.

Desgraciadamente, tan sólo tres cortas campañas de excavación pudieron ser efectuadas en los años 1955, 1957 y 1966 por el Servicio de Investigación Prehistórica de Valencia, a cargo de D. Enrique Pla en colaboración con D. Miguel Tarradell. Estas excavaciones evidenciaron la existencia en el istmo de diferentes estructuras constructivas y de un considerable volumen de material arqueológico en su mayor parte inédito ${ }^{2}$. Si fue publicado, en cambio, el estudio del conjunto numismático (Mateu y Llopis, 1972), el cual da una amplia cronologia al yacimiento, que, iniciándose en época alto-imperial, tendria un florecimiento en el si-

: Noticias anteriores a la excavación sobre la existencia del yacimiento:

Mateu y Llopis, F.: "En el antiguo Seno Sucronense. L'Illa de Culleran. B.S.C.C., XXV. 1949, págs. 126-129.

Fletcher, D.: «Cullera.Punta de I'Illa». N.A.H., III-IV. (1954-1955), 1956, págs. 288.

Noticias de las excavaciones, en:

Pla Ballester, E.: "Actividades del SIP, 1946-1955», APL. VI. 1957, pág. 207.

Pla Ballester, E.: «Actividades del SIP, 1956-1960", APL, IX, 1961, pág. 220.

Pla Ballester, E.: «Actividades del SIP, 1972», APL, XIII, 1972, págs. 294-295. 


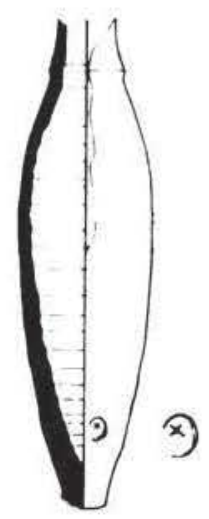

F16 2

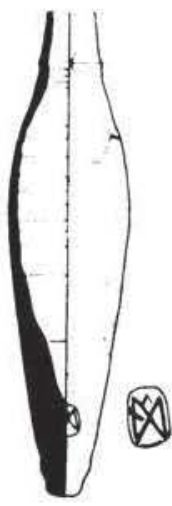

F10 22

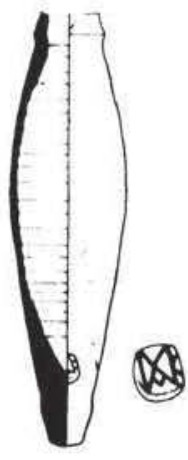

F10 2.3

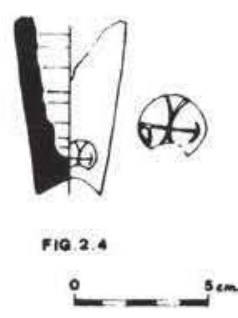

Figura 2.-Ungüentarios procedentes de Cullera. E. 1/4. glo Iv d. C. para perdurar hasta la época de Justiniano de Bizancio, detectándose un período de influencia vándala a partir del 460 , atestiguado por la presencia de 51 monedas emitidas por el reino vándalo del norte de África, correspondiendo las últimas emisiones a Gelimer $(530-533$ d. C.). La cronologia de los hallazgos numismáticos se cerraría con el hallazgo aislado de una moneda de Wamba.

Las someras noticias publicadas sobre el yacimiento, unidas a la total destrucción del mismo en la década de los 60 , han hecho que la bibliografía no se ocupara prácticamente del mismo. Tan sólo el Dr. E. Llobregat ha mostrado siempre el mayor interés, dando noticias de dos cruces litúrgicas de bronce allí encontradas y defendiendo el carácter religioso de las instalaciones ubicadas en la isla, isla que cree posible relacionar con la que aparece mencionada en el epitafio del obispo Justiniano de Valencia y, consiguientemente, poner en relación las estructuras de l'Illa de Cullera con el cenobio fundado por este obispo en memoria del mártir San Vicente ${ }^{3}$.

\footnotetext{
${ }^{3}$ Ver principalmente:

Llobregat, E.: «San Vicente Mártir y Justiniano de Valencia", Homenaje a Fray Justo Pérez de Urbel. OSB, t. II, 1977, págs. 7-18.

Llobregat,-E.: La primitiva Cristiandat Valenciana. Valencia, 1977.
}

Asimismo, hay que añadir un reciente estudio del material anfórico de este yacimiento, el cual proporciona una cronologia centrada en la segunda mitad del siglo vi d. C. (García y Rosselló, 1992). Es en este contexto del siglo vı d. C. donde se incluyen los ungüentarios cerámicos objeto de este artículo.

\section{DESCRIPCIÓN DE LAS PIEZAS}

(Figuras 2 y 4 )

Figura 2.1. Pieza consolidada, incompleta, no conserva el borde. Altura conservada: 18.1 $\mathrm{cm}$. Anchura máxima: $5 \mathrm{~cm}$. Pasta de coloración rosada, compacta, dura y bien depurada, con algunas inclusiones apenas visibles de partículas de cal. Superficie interna de color rosado, rugosa y con las líneas de torno muy marcadas. Superficie externa de tonalidad rosaanaranjada, alisada, aunque son visibles raspaduras, huellas digitales y manchas de arcilla. Conserva restos de un engobe muy ligero de coloración rojo-anaranjada. Cerca de la base presenta una estampilla muy deteriorada, poco

Llobregat, E.: «La más antigua cristiandad», Historia del Pueblo Valenciano, vol. I, 1988, págs. 141-160.

Llobregat, E.: "Las cruces de la Punta de I'Illa (Cullera)», Trabajos Varios del SIP, núm. 89, 1992, págs. 663-670. 
visible, de forma circular y con un motivo cruciforme.

Figura 2.2. Pieza incompleta, consolidada, no conserva el borde. En realidad se trata de dos fragmentos pero que se incluyen juntos en el mismo dibujo, pues presentan las mismas características y es más que probable que formaran parte de la misma pieza, indicando el punto de fractura. Altura conservada: $17.8 \mathrm{~cm}$. Anchura máxima: $4.4 \mathrm{~cm}$. Pasta de coloración rosada, compacta, dura y bien depurada con escasas impurezas apenas visibles de partículas de cal. Superficie interna de color rosado, rugosa y con líneas de torno muy marcadas. Superficie externa de tonalidad rosa-anaranjada, fina, con algunas raspaduras y huellas digitales. Presenta un ligero engobe rojo-anaranjado en la pared externa de la parte superior de la pieza, cayendo en forma de goterones hacia el inferior de la misma. Próxima a la base aparece una estampilla, un tanto deteriorada, de forma rectangular y con motivo monogramático.

Figura 2.3. Pieza consolidada, incompleta y cuya mitad inferior aparece quemada. Pasta de color anaranjado, dura, compacta y bien depurada, con escasas particulas de cal. Superficie interna de color anaranjado y con líneas de torno muy marcadas. Superficie externa de tonalidad anaranjada, alisada, presentando raspaduras, huellas digitales y restos de arcilla. Conserva parte de un engobe de color rojizo en la superficie externa, cayendo en forma de goterones por la zona inferior de la pieza. Cerca de la base aparece una estampilla cuadrangular con motivo monogramático muy similar al de la fig. 2.2, pero en posición invertida respecto a ésta.

Figura 2.4. Fragmento de la parte inferior de un ungüentario. Altura conservada: $6.4 \mathrm{~cm}$. Pasta gris azulada, dura, compacta y bien depurada, no apreciándose impurezas. Superficie interna de color beige-anaranjado claro, líneas de torno marcadas. Superficie externa de color gris con manchas anaranjadas, alisada. Presenta una estampilla circular monogramática.

\section{COMENTARIO}

Este tipo cerámico fue individualizado por J. W. Hayes en un nivel del siglo vil d. C. en la iglesia de San Polyeuktos de Saraçhane, Estambul. De ahi proceden tres ejemplares casi completos, dos de ellos con estampilla, asi como 20 bases estampilladas y alrededor de $45 \mathrm{sin}$ estampillar (Hayes, 1968: 214). En un artículo posterior, el autor recoge los principales hallazgos conocidos, realizando un mapa de distribución y una lista de los mismos, evidenciando una amplia circulación en toda la cuenca del Mediterráneo oriental y una particular concentración en puntos costeros de Grecia y Turquía (Constantinopla, Rodas, Éfeso, Atenas, Kythera...), asi como algunos ejemplares de Palestina, la región de Alejandría y Libia; situando también los hallazgos más esporádicos del Mediterráneo occidental: Norte de África, Sicilia y Marsella (Hayes, 1971: 247-248, figura 3 ).

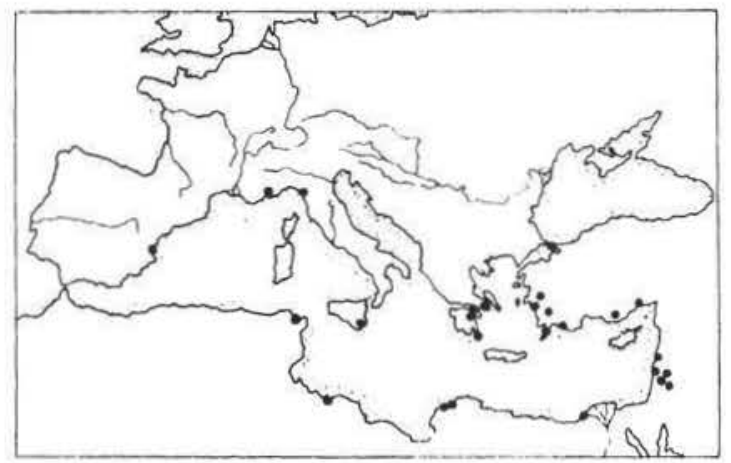

Figura 3.-Distribución geogrática de los ungüentarios conocidos.

La cronología propuesta por Hayes a partir de los ejemplares citados se sitúa alrededor del 500/520-650 d. C., siendo los ejemplares estampillados propios del siglo vi ya que las piezas datadas en el siglo vII no suelen llevar estampillas, aunque la sola ausencia de las mismas no implica que éstos sean tardíos. El final de esta producción cerámica cabe situarla alrededor del $650 \mathrm{~d}$. C. como consecuencia de la conquista árabe de Palestina (Hayes, 1971: 245).

Más recientemente, Lusuardi y Murialdo (1991: 123-124, lám. 1, 1-4) amplian la carta de distribución realizada por Hayes de esta cerámica añadiendo los ejemplares de Luni, tres 


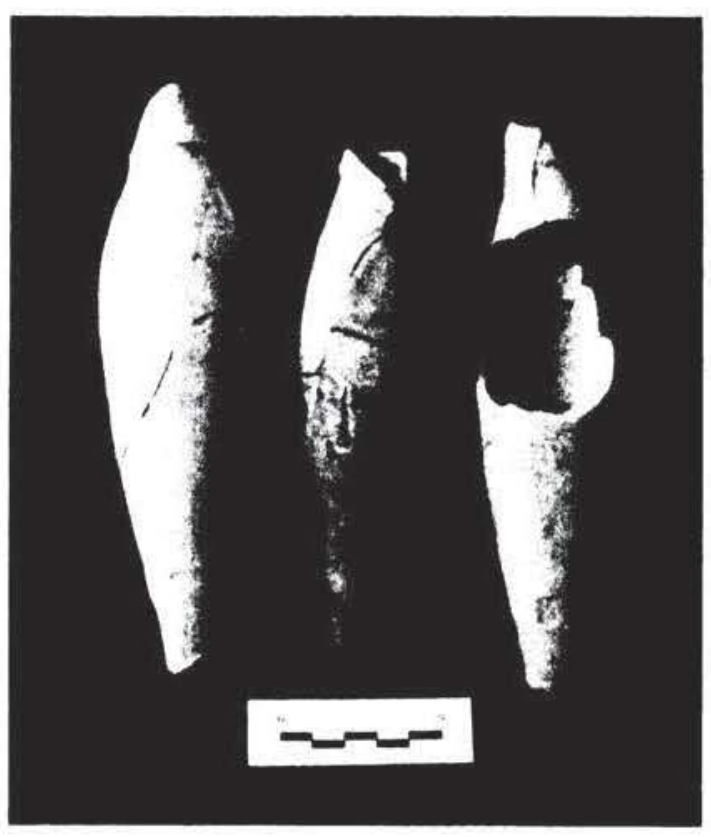

Figura 4,- Ungüentarios de Cullera, piezas I a 3.

piezas sin estampillar aparecidas en un contexto de finales del siglo vi d. C.

Apuntar por nuestra parte la presencia de otro ejemplar con estampilla cuadrangular hallado en la Basílica de San Juan de Éfeso (Parman, 1989: 280, fig. 6a). Así mismo, a los ejemplares palestinos recogidos por Hayes provenientes de Bethany (Saller, 1957: 224-225, lám. 110d) y Dhiban (Tushingham, 1972: 159, fig. 13,80 y lám. XXIII,7), habria que añadir la pieza proveniente de Cesarea (Riley, 1975: 3537, n. ${ }^{\circ} 40$ ), Ramat Rahel (Aharoni, 1962: fig. 17.21) y en la ciudad de Jerusalén en las excavaciones de "The Armenian Garden» (Tushingham, 1985: 321, fig. 30.18), en la "City of David" (Magness, 1989: 60, 112; fig. 43.13), en el "Jewish Quarter» (Magness, 1989: 188-189, 233; fig. 51.29) y el publicado por Ben-Dov (1985: 255. Citado en Magness, 1989: 189), muy interesante por llevar una estampilla que hace mención a un obispo, similar a un ejemplar hallado en Rodas (Hayes, 1971: 244, lám. 37b). Todos los ejemplos citados se ajustan a la cronología propuesta por Hayes de los siglos vi y vil d. C. (fig. 3).
Por lo que respecta al lugar de producción. las evidencias con las que contamos son variadas y su origen oriental queda fuera de toda duda. Por una parte, su distribución refleja una profusión de hallazgos en centros costeros del Mediterráneo oriental, en una zona de dominio directo del Imperio Bizantino durante los siglos Iv al vil d. C. Hayes, aunque reconoce que el lugar exacto de su producción no está totalmente definido, en base a la uniformidad de su manufactura supone un único origen. De entre las producciones del Mediterráneo oriental su fábrica se asemeja mucho a un tipo de cerámica pintada tardia, la Ware $X$ de Nessana, muy característica de los yacimientos de la región del Negev (Baly, 1962: 278-279). Cerámica de similar factura, aunque sin decoración pintada, también aparece en Dhiban, Jordania (Hayes. 1971: 246). Asi mismo, en el reciente estudio de Magness sobre la cerámica romana-tardía y bizantina de Jerusalén, queda patente que el tratamiento superficial de goterones de engobe oscuro, típico de la producción de LRU, se corresponde bien con la tradición cerámica romana-tardia de Jerusalém (Magness, 1989: 189). Por otra parte, la presencia de las estampillas con caracteres griegos en muchos de los ejemplares documentados vienen a avalar un origen oriental para esta producción cerámica. Los monogramas que aparecen en algunas de las estampillas son característicos y comunes en capiteles de columnas, monedas, vajilla de plata (Cruikshank, 1964 y 1968), anillos (Dalton, 1901), popularizándose durante el periodo del 450-650 d. C. (Hayes, 1971: 245).

Asimismo, es bastante común la aparición de estampillas similares en otros tipos de producciones cerámicas de origen palestino, como las ánforas tipo Palestinian Bag-Shaped (Aharoni, 1964: fig. 9.4 y 9.5), cerámica común (Bagatti, 1983: 130, lám. 19). Del mismo modo, son muy frecuentes en algunos tipos de lucernas palestinas muy comunes en el periodo bizantino la aparición de fórmulas religiosas, peculiares ligaturas, símbolos y letras retrógradas, motivos que como ya hemos visto aparecen en las estampillas de los ungüentarios (Loffreda, 1985; Magness, 1989: 837-852).

Hay que hacer notar la existencia de otro 
tipo de ungüentario tardio, similar tipológicamente al que aqui nos ocupa, pero distinguible por el tipo de arcilla micácea y que también aparece en similares contextos, aunque numéricamente en menor proporción (Hayes, 1968: 214) y que tendría un origen externo a la zona de Palestina, pues las pastas micáceas no son comunes en esta parte (Magness, 1989: 189) y quizás haya que buscar su origen en la zona del Egeo o el área microasiática, donde las arcillas micáceas son propias de estas regiones (Williams, 1983: 103-104). Esta variante de pasta micácea se documenta en el Ágora de Atenas (Robinson, 1959: Grupo M, n. ${ }^{\circ} 369$, pág. 118 , lám. 34) datado a finales del siglo VI d. C. y en el Hipódromo de Cesarea (Riley, 1975: 37, tipo A n. ${ }^{\circ}$ 39).

Su forma, pequeña capacidad y su solidez apuntan hacia un preciado contenido $y$, aunque no contamos con evidencias directas, se ha supuesto que pudieron tener alguna finalidad religiosa y haber servido para contener agua del Jordán, aceite sagrado de alguno de los grandes santuarios de Tierra Santa o algo similar, en cualquier caso, relacionado con alguna ceremonia concreta de la liturgia cristiana como el bautismo o la ordenación de clérigos, aunque la porosidad de estos recipientes los hace más aptos para contener aceite que agua ( $\mathrm{Ha}-$ yes, 1971: 244, 246).

Algún indicio indirecto sobre la función de estos ungüentarios nos lo proporcionan dos ejemplares que en sus respectivas estampillas llevan sendas inscripciones en griego que contienen el título de una jerarquía eclesiástica (obispo) y el nombre del mismo en genitivo. Uno de ellos proviene de Rodas y en la estampilla se lee «del obispo Severiano" (Hayes, 1971: 244, lám. 37b), el otro es originario de Jerusalén y como el anterior hace referencia a un obispo (episkopou -erasinou) (Magness, 1989: 189). La presencia del nombre de un obispo es, según Hayes, muy significativa y confirmaría el valor del contenido y el especial interés de la Iglesia por el mismo, apuntando incluso que la propia Iglesia podría participar en su distribución y venta, aunque es probable que no tuvieran un uso exclusivamente litúrgico y también fueran utilizados con propósitos medicinales, con la creencia, muy extendida en aquella época, en las propiedades terapéuticas del aceite santificado (Hayes, 1971: 247; Elvira, 1985: 7).

Por último, únicamente apuntar que la presencia de estos ungüentarios cerámicos, junto a otra serie de objetos litúrgicos aparecidos en Punta de l'Illa de Cullera, vienen a reforzar la idea defendida por el Dr. Llobregat del carácter religioso del asentamiento y su posible conexión con el monasterio aludido en el epitafio del obispo Justiniano de Valencia ${ }^{4}$.

\section{BIBLIOGRAFÍA}

Aharoni, Y., 1962: Excavations at Ramat Rahel, Centro de Studi Semitici, Roma.

Alaroni, Y., 1964: Excavations at Ramat Rahel, Centro de Studi Semitici, Roma.

Baciattı, B., 1983: Antichi villaggi cristiani di Giudea e Neghev, Studium Biblicum Franciscanum, Collectio Minor 24, Jerusalén.

BALY, T. J., 1962: «Pottery», págs. 271-282, en: Excavations at Nessana, vol. 1, H.D. Colt (ed.), British School of Archaeology in Jerusalem, Londres.

BEN-Dov, M., 1985: In the Shadow of the Temple, Keter Publishing House Jerusalem, Jerusalén.

Cruikshank, E., 1964: «Byzantine Silver Stamps: Supplement 1», Dumbarton Oaks Papers, XVIII, págs. 239-248, Washington D.C.

Cruikshank, E., 1968: «Byzantine Silver Stamps: Supplement II», Dumbarton Oaks Papers, XXII, págs. 143-149, Washington D.C.

Dalton, O. M., 1901: Catalogue of Early Christian Antiquities and Objects from the Christian East, British Museum, Londres.

Elvira, M. A., 1985: «Viejos < souvenirs> de Tierra Santa», Revista de Arqueología, n. 52, págs. 6-13, Madrid.

Garcia, I., Rosselló, M., 1992: «Las ánforas tardorromanas de Punta de l'Illa de Culle-

4 Una primera aproximación al estudio de los objetos litúrgicos y de los restos de estructuras aparecidos en el yacimiento, ha sido presentada en la IV Reunió d'Arqueologia Cristiana Hispànica, Lisboa, 1992 (Rosselló, en prensa). 
ra», Trahajos Varios del SIP, núm. 89, págs. 639-661, Valencia.

Hayfs, J. W., 1968: «Excavations at Saraçhane in Istambul.Fifth Preliminary Report», Dumharton Oaks Papers, XXII, págs. 194216, Washington D.C.

Hayes, J.W., 1971: «A New Type of Early Christian Ampullan, British School at Athens, vol. 66. págs. 243-248.

LOFFREDA, S., 1985: Lucerne Bizantine in Terra Santa con Inscrizioni in Greco, Studium Biblicum Franciscanum, Collectio Maior, n. ${ }^{\circ} 35$, Jerusalén.

Lusuardi, S., y Murialdo, G., 1991: «Le ceramiche mediterranee in Liguria durante il periodo bizantino (VI-VII secolo)", págs. 123146, en: A cerámica medieval no Mediterrâneo occidental, Actas do IV Congresso Internacional, Lisboa, 16-22 de Novembro 1987.

Maginiss, J., 1989: A Typology of the Late Roman and Byzantine Pottery of Jerusalem, University of Pennsylvania, University Microfilms International, Ann Arbor (1991), 2 vols.

Matfu y Llopis, F., 1972: «Bronces romanos imperiales y vándalos en l'Illa de Cullera», Archivo de Prehistoria Levantina, XIII, págs. 241-256, Valencia.

Parman, E., 1989: «The Pottery from St. John's Basilica at Ephesos», págs. 277-289, en:
Recherches sur la Céramique Bvaantine, Bulletin de Correspondance Hellénique, suppl. XVIII, École Française d'Athènes.

RILI:Y, J., 1975: «The Pottery from the First Session of Excavation in the Caesarea Hippodrome», Bulletin of the American Sihools of Oriental Research. 218 , págs. 25-63.

Robinson, H. S., 1959: Pottery of the Roman Period. The Athenian Agora, vol. 5, American School of Clasical Studies at Athens, Princeton.

Rossflló, M., (en prensa): «Punta de l'llla de Cullera (Valencia): Un posible establecimiento monástico del s. vi d. C.», IV Reunió d'Arqueologia Cristiana Hispànica, 28 septiembre/2 de octubre, 1992, Lisboa.

Salle: S. J., 1957: Excavations at Bethany (1949-1953), Studium Biblicum Franciscanum, 12, Jerusalén.

Tushingham, A. D., 1972: The Excavations at Dibon (Dhibân) in Moab. Third Campaign. 1952-53, Annual of the American Schools of Oriental Research, 40.

Tushingham, A. D., 1985: Excavations in Jerusalem, 1961-1967, vol. I, Royal Ontario Museum, Toronto.

Williams, D. F., 1983: «The Petrology of Certain Byzantine Amphorae: Some Suggestions as to Origins», págs. 99-110, en: Actes du colloque sur la céramique antique, (Carthage, 23-24 juin 1980), Dossier 1, CEDAC.

\title{
UN TIPO DE ÁNFORA TARDO-ROMANA POCO CONOCIDO (VLR 8.198)
}

\author{
POR \\ JOSEP ANTON REMOLÀ VALLVERDÚ \\ CODEX sccl-Arqueologia i Patrimoni
}

RESUMEN

El estudio de las ánforas procedentes de diversos depósitos bajo-imperiales (siglo $v$ d. C.) excavados recientemente en Tarragona permite caracterizar un tipo de ánfora poco conocido (VLR 8.198), de origen posiblemente oriental, cuya presencia en estos contextos tarraconenses representa un $2,6 \%$ sobre el número total estimado de ejemplares de ánfora (606).

\section{SUMMARY}

The study of amphorae from several late Roman contexts (fifth century $A D$ ), recently excavated at Tarragona, allows to characterize an unknown type (VLR 8.198), possibly originated in Eastern Mediterranean. It comprises $2,6 \%$ of all estimated samples (606). 